\title{
A SOMAESTÉTICA E A FILOSOFIA PRAGMATISTA DE RICHARD SHUSTERMAN: UMA ENTREVISTA
}

\section{Richard Shusterman}

Florida Atlantic University

shuster1@fau.edu

\section{André Azevedo Marques Estevez}

Universidade de São Paulo

andre_estevez@usp.br

\author{
Marília Velardi \\ Universidade de São Paulo \\ marilia.velardi@usp.br
}

\begin{abstract}
Resumo: Richard Shusterman é professor de Filosofia na Florida Atlantic University. Sua filosofia é fortemente influenciada pela obra de William James e John Dewey e o estudo desses autores, somados à sua experiência com Educação Somática e outras práticas corporais, fizeram com que o filósofo desenvolvesse uma nova proposta: a Somaestética. A Somaestética é um campo interdisciplinar dedicado ao estudo das possibilidades e capacidades de percepção e apreciação estética do corpo, ou melhor, do soma. Buscando compreender como sua história se relaciona com o desenvolvimento da sua teoria e quais os rumos que a Somaestética tem tomado, especialmente na sua conexão com as artes, realizamos a entrevista que traduzimos para o português e disponibilizamos a seguir. As duas últimas questões referem-se ao universo do canto, por ser essa a área de estudo na qual nós nos centrávamos naquele momento. No entanto, acreditamos que o comentário do filósofo sobre o assunto pode ser esclarecedor e enriquecedor para questões que estejam para além dessa área específica.
\end{abstract}

Palavras-Chave: Somaestética. Estética. Corpo. Educação Somática.

\section{SOMAESTHETICS AND RICHARD SHUSTERMAN'S PRAGMATIST PHILOSOPHY: AN INTERVIEW}

Abstract: Richard Shusterman is a Professor of Philosophy at Florida Atlantic University. His philosophy is strongly influenced by the works of William James and John Dewey; and the study of these authors, added to his own experience with Somatic Education and other bodily practices, led him to develop a new project: Somaesthetics. Somaesthetics is an interdisciplinary field devoted to the study of possibilities and capacities of perception and aesthetic appreciation of the body, or even better, the soma. Seeking to understand how his personal history relates to the developing of his theory and through what paths somaesthetics has been traveling, especially in its connection to the arts, we made the interview that we have translated into Portuguese and provide hereafter. The last 
two questions refer to the universe of singing, because this was the field of study to which we were devoted at the time we did the interview. However, we believe the notes that the philosopher has made about the subject may be enlightening and enriching for issues that may be beyond this specific field.

Keywords: Somaesthetics. Aesthetics. Body. Somatic Education.

Richard Shusterman é filósofo, estudioso eminente Dorothy F. Schmidt nas Humanidades ${ }^{1}$ e Professor de Filosofia na Florida Atlantic University, em Boca Raton, Florida, Estados Unidos. Formou-se magna cum laude em Inglês e Filosofia pela Universidade Hebraica de Jerusalém, onde também realizou seu mestrado em Filosofia, também com a distinção magna cum laude. Posteriormente, tornou-se doutor em Filosofia pela St. John's College, na Universidade de Oxford, sob a supervisão de James Opie Urmson. Iniciou sua carreira dedicando-se à filosofia analítica, migrando, posteriormente, para os estudos pragmatistas. Richard Shusterman escreveu mais de duzentos artigos e tem mais de vinte livros publicados, dos quais apenas dois foram traduzidos para o português e lançados no Brasil: Vivendo a Arte $^{2}$ e Consciência Corporal ${ }^{3}$. Sua filosofia é fortemente influenciada pela obra de William James e John Dewey e o estudo desses autores, somados à sua experiência com Educação Somática ${ }^{4}$ e outras práticas corporais, fizeram com que ele desenvolvesse uma nova proposta: a Somaestética. A Somaestética é um campo interdisciplinar dedicado ao estudo das possibilidades e capacidades de percepção e apreciação estética do corpo, ou melhor, do soma. Richard Shusterman é também professor da Florida Atlantic University, onde dirige o "Centro para o Corpo, Mente e Cultura 5 ", do qual foi fundador e que lhe permite avançar em sua pesquisa Somaestética, bem como difundir os seus estudos com a comunidade acadêmica internacional. Ali Richard Shusterman recebe frequentemente professores colaboradores de diversos países que buscam estudar a sua obra e o conceito criado por ele.

Nos textos que amparam a proposição da Somaestética como um campo interdisciplinar, Shusterman também se dedica a questionar o papel negativo que, muitas vezes, a Filosofia atribui à consciência somática. Para isso o autor revisa criticamente os argumentos de diversos pensadores que, de alguma maneira, já

\footnotetext{
1 "Dorothy F. Schmidt Eminent Scholar in the Humanities", no original em inglês.

2 SHUSTERMAN, Richard. Vivendo a Arte: o pensamento pragmatista e a cultura popular. São Paulo: Ed. 34, 1998. Tradução: Gisela Domschke. O título original em inglês é 'Pragmatist aesthetics', publicado em 1992.

3 SHUSTERMAN, Richard. Consciência Corporal. Trad.: Pedro Sette-Câmara. Rio de Janeiro: É Realizações, 2012a. O título original em inglês é 'Body Consciousness - A Philosophy of Mindfulness and Somaesthetics', publicado em 2008.

${ }^{4}$ A Educação Somática é um campo interdisciplinar que visa, segundo Hanna (1991, pag. 31), "estudar o soma: ou seja, o corpo como percebido de dentro via percepção pessoal". O termo somático foi resgatado por Thomas Hanna na década de 70.
}

5 "Center for Body, Mind and Culture", no original em inglês. 
trataram do assunto, buscando fomentar, no escopo da Filosofia, uma nova importância ao corpo e às suas capacidades perceptivas.

Essa proposta chamou a atenção do grupo de estudos ECOAR $^{6}$ (Estudos em Corpo e Arte), devido a sua forte conexão com as práticas somáticas, especialmente com o Método Feldenkrais ${ }^{7}$, que está presente em muitas das nossas investigações teóricas e aplicadas no campo das Artes da Cena. A partir dessa primeira aproximação nós percebemos de quais maneiras o pensamento do autor conectavase aos nossos estudos ao nos trazer uma abordagem filosófica capaz de amparar reflexões sobre os sentidos, usos e papéis do corpo e do soma nos estudos e nas práticas artísticas. Como consequência, nós passamos a trazer os seus escritos para as discussões no grupo e para a reflexão sobre as pesquisas acadêmicas que realizávamos. Na época, André Estevez estudava a Somaestética como um dos referenciais teóricos de sua investigação de mestrado. Assim, decidimos que seria interessante o aprofundamento dos seus estudos em contato direto com o professor Shusterman, o que aconteceu, graças a sua boa-vontade e recepção e ao apoio financeiro disponibilizado pela Fundação de Amparo à Pesquisa do Estado de São Paulo, que concedeu ao aluno uma Bolsa de Estágio de Pesquisa no Exterior $\left(\mathrm{BEPE}^{8}\right)$.

André permaneceu no "Centro para o Corpo, Mente e Cultura", assistindo às aulas e palestras e mergulhando no estudo somaestético durante o segundo semestre de 2016. Nesse período nos demos conta de que mesmo quando esteve no Brasil na ocasião do lançamento do seu livro Vivendo a Arte, não foi produzida entrevista com Richard Shusterman publicada em português, com exceção de uma breve feita para a Folha de São Paulo, em maio de $1998^{9}$. Assim, acreditamos que seria uma ideia interessante produzir esse material e disponibilizá-lo à comunidade acadêmica brasileira.

Buscando compreender como a sua história relaciona-se ao desenvolvimento da sua teoria e quais os rumos que a Somaestética tem tomado, especialmente na sua conexão com as artes, realizamos a entrevista com o professor Shusterman que

\footnotetext{
${ }^{6}$ O ECOAR - Grupo de Estudos em Corpo e Arte - está sediado na Escola de Artes, Ciências e Humanidades da Universidade de São Paulo. É formado por alunos, ex-alunos, artistas e pesquisadores do campo do Movimento Humano, especialmente interessados nas epistemologias que conduzam ao desenvolvimento de investigações qualitativas e radicalmente qualitativas. Atualmente o ECOAR tem como focos: (a) a busca de epistemologias artísticas, (b) a construção de conhecimento com artistas sobre a arte e (c) a criação de estruturas de performances dos "dados" ou dos conhecimentos produzidos nas investigações.
}

7 O Método Feldenkrais é uma prática de Educação Somática desenvolvida por Moshé Feldenkrais. Como define Ralph Strauch (1996, p.1, tradução nossa),

É um modo de aprender - aprender a mover-se com mais facilidade e liberdade, a carregar menos estresse em seu corpo, a parar de fazer coisas que lhe causam dor. [...] aprender que você sabia quando era criança, mas perdeu contato ao crescer.

O método compreende duas abordagens distintas, uma chamada 'Consciência pelo Movimento', cujas lições são aplicadas pelo uso de instruções verbais, e outra denominada 'Integração Funcional', que é aplicada pela intervenção do toque do instrutor na pessoa que está vivenciando o método. Em ambos, o objetivo é o mesmo, melhorar as ações pelo aprimoramento da autoimagem.

8 Processo 2016/12887-8

${ }^{9}$ Leia a entrevista aqui: <http://www1.folha.uol.com.br/fsp/ilustrad/fq21059820.htm>. Acesso em: 10 ago. 2017. 
traduzimos para o português e disponibilizamos a seguir. A entrevista foi respondida por escrito o que, segundo ele, permitiria respostas mais completas e cuidadosas. Assim, enviamos uma série de questões por e-mail, as quais o professor respondeu e nos enviou no dia 28 de dezembro de 2016. Após a nossa leitura, organização do material, tradução e redação do manuscrito em português nós novamente traduzimos para o inglês e enviamos o texto mais uma vez ao professor Shusterman que completou algumas informações e nos enviou o novo material em 8 de agosto de 2017. Traduzimos novamente para o português e este é o material que ora apresentamos.

As duas últimas questões da entrevista referem-se ao universo do canto, por ser essa a área de estudo na qual nos centrávamos naquele momento. No entanto, acreditamos que o comentário de Richard Shusterman sobre o assunto pode ser esclarecedor e enriquecedor para questões que estejam para além dessa área específica.

ECOAR - Nós gostaríamos de iniciar esta entrevista falando um pouco sobre sua decisão de se tornar um filósofo: o que o fez escolher este caminho para a sua vida? Também, o que o fez decidir tornar-se professor na universidade?

Richard Shusterman - Eu fui um adolescente rebelde, deixei a casa dos meus pais na Filadélfia em 1966 quando eu tinha dezesseis anos; eu era crítico dos valores e das autoridades e instituições da sociedade dos Estados Unidos, assim como muitos jovens estadunidenses nos anos 60 . Sendo um jovem rebelde, eu me simpatizei e li com gosto alguns filósofos particularmente críticos dos valores estabelecidos e da autoridade social: pensadores como Sócrates, Rousseau, Nietzsche e Camus. Depois de sair da casa dos meus pais, eu fui parar em Israel, que era, na época, uma sociedade socialista muito aberta e progressista, e um lugar que me ofereceu abrigo e suporte, incluindo uma formação universitária. Também era fascinante intelectualmente, para mim, aprender uma nova cultura e um novo idioma. Havia um prazer em tornar-me uma nova pessoa, transformando-me em algo diferente da pessoa que havia sido formada originalmente pelo meu lar e pela cultura nacional original. Eu vivi um forte sentido de autonomia e de liberdade.

Então eu permaneci em Israel, primeiro estudando filosofia na Universidade Hebraica de Jerusalém (onde foquei em filosofia analítica, porque era isso o que os melhores professores estavam fazendo) e depois servindo como oficial na inteligência militar das Forças de Defesa de Israel por três anos (1973-1976). Foi durante o período do serviço militar (uma experiência muito rica e recompensadora, mas que também levantou muitas questões existenciais sobre o significado e o valor da vida e sobre os valores que clamam por suplantar os valores da vida) que eu decidi tentar fazer da filosofia a minha carreira. Embora eu gostasse da intensidade da ação na vida militar, eu sentia falta do envolvimento com ideias abstratas e textos imaginativos, argumentos belamente estruturados numa linguagem belamente escrita. A beleza das ideias filosóficas sempre me atraiu tanto quanto suas alegadas verdades. Esse é o motivo pelo qual eu fiz da estética e da cultura o maior foco do meu trabalho filosófico. Depois do exército eu fui para Oxford completar meus estudos filosóficos (trabalhando com estética com o filósofo analítico J. O. Urmson) e concluí meu doutorado em Oxford em 1979. Na época, como agora, não era fácil encontrar um bom trabalho universitário como filósofo, mas eu tive muita sorte em conseguir um. Em 1980 eu iniciei minha carreira universitária na Universidade Ben- 
Gurion do Neguev, onde eu fui promovido e me tornei professor permanente ${ }^{10} \mathrm{em}$ 1984. Mas eu abdiquei da minha posição para tornar-me professor de filosofia na Universidade Temple ${ }^{11}$, na Filadélfia, porque este era, talvez, o melhor centro de estética no mundo inteiro. Eu sou feliz por ter escolhido uma carreira universitária em vez da carreira militar, mas meus anos militares ensinaram-me uma lição importante sobre a vida acadêmica: não levar muito a sério seus jogos de poder e de prestígio. Tais jogos e estruturas de poder são muito triviais comparados àquilo que eu experimentei no exército israelense.

E - Você pode nos contar mais sobre a sua trajetória acadêmica? Como conquistou a sua posição atual como Estudioso Eminente Dorothy F. Schmidt nas Humanidades ${ }^{12}$, e como se deu a criação do 'Centro para o Corpo, Mente e Cultura' aqui na Florida Atlantic University?

R.S. - Eu fiz do Departamento de Filosofia da Universidade Temple a minha base de operações por muitos anos, mas eu também atuei diversas vezes como professor visitante, passando muitos anos em Paris, Berlim e Hiroshima. Depois de quase vinte anos em Temple (sendo os últimos seis anos como chefe do departamento), eu estava pronto para uma mudança. A essa altura eu já tinha começado a desenvolver o meu conceito de Somaestética e também já havia reconhecido que ela era um campo interdisciplinar para muito além da filosofia. Quando a Florida Atlantic University, uma universidade dinâmica e jovem na bela e tropical cidade de Boca Raton, me ofereceu uma bem remunerada cadeira profissional nas Humanidades, eu decidi me mudar para lá. Com o financiamento generoso que veio com o cargo, eu pude criar o Centro para o Corpo, Mente e Cultura que me permite organizar programas interdisciplinares e trabalhar com professores visitantes de fora do campo da filosofia. O sul da Flórida é também bem característico em três áreas que são centralmente relacionadas à Somaestética: os esportes (porque o clima quente da Flórida torna possível a prática de esportes ao ar livre durante $o$ ano todo), a geriatria (porque o clima quente atrai uma grande população de idosos que podem se beneficiar do cuidado somaestético) e o campo da cirurgia cosmética (devido a uma mentalidade ligada ao glamour de Miami e ao fato de que há mais consciência corporal quanto mais frequentemente se expõe o corpo, o que se deve ao clima quente e à cultura praiana). Eu imagino que você deva entender um pouco disso por causa da cultura brasileira - embora, a esse respeito, São Paulo seja, provavelmente, diferente do Rio ou da Bahia.

E - Ao lermos os seus livros, artigos e assistindo as suas palestras e aulas, parece-nos que a biografia é algo muito importante para você, que sempre conecta o trabalho dos filósofos e outros pensadores com as suas histórias e os fatos de suas vidas. Isso é algo que vem dos seus estudos pragmatistas, considerando a filosofia como arte da vida? Ou é outra coisa?

\footnotetext{
10 "where I was promoted and tenured", no original em Inglês.

11 Temple University, no original em inglês, é uma universidade localizada na Filadélfia, Pensilvânia, nos Estados Unidos.

12 "Dorothy F. Schmidt Eminent Scholar in the Humanities", no original em inglês.
} 
R.S. - A ideia de conectar os pensamentos de um filósofo com a sua vida é tão velha quanto a própria filosofia. Lembre-se que Sócrates não escreveu nenhum livro ou artigo; sua filosofia era incorporada em sua vida; ele ensinou pelo seu exemplo de vida - uma vida de discussões e pensamentos críticos corajosos. A filosofia era o estudo do como viver da melhor forma e os seus estudos acerca da verdade, conhecimento, virtude, beleza e justiça foram formados ou guiados por como estes valores poderiam contribuir para um viver aprimorado. A ideia de separar a filosofia da vida, por concebê-la como um assunto meramente teórico - e que ainda é assim ensinado na Universidade - é, essencialmente, uma ideia moderna. No entanto, alguns grandes pensadores modernos continuaram a afirmar este antigo conceito de filosofia. Nietzsche argumentou que a filosofia é essencialmente uma biografia disfarçada. Foucault também reconheceu o valor de interpretar a filosofia como modo de vida; ele era encorajado nesta ideia (e provavelmente direcionado a ela) por Pierre Hadot, um colega de Foucault no Collège de France, que se especializou em filosofia antiga. Entre Nietzsche e Foucault estavam pragmatistas como William James e John Dewey ${ }^{13}$ que também viam a filosofia como algo que deveria servir para aprimorar a qualidade das experiências e vidas das pessoas. Este é o importante impulso meliorista do pragmatismo $^{14}$.

E - No prefácio do seu livro 'Thinking through the body' você diz que o seu interesse pela Estética emergiu de "arrebatamentos, na infância, de encantos corporais radiantes e uma satisfação somática extremamente feliz que me marcaram com um anseio contínuo por beleza, muito antes de eu saber de qualquer distinção entre corpo e alma (SHUSTERMAN, 2012b, p. ix) ${ }^{15}$ ". Embora você tenha começado a sua carreira como filósofo analítico, você acabou, posteriormente, mudando o seu foco, tornando-se um filósofo pragmatista ${ }^{16}$. A maior parte do seu trabalho como filósofo pragmatista tem sido dedicada ultimamente à Somaestética. Além das suas experiências somáticas na infância e dos seus estudos pragmatistas, você é um praticante de Feldenkrais e já teve também experiências com a Técnica de Alexander e com práticas Zen. Como as práticas somáticas, seus pensamentos filosóficos e o seu histórico acadêmico entrelaçam-se para formar a Somaestética? Foram algumas dessas experiências, ou alguma outra, que o instigaram a devotarse à criação da Somaestética?

R.S. - Minha referência a "arrebatamentos, na infância, de encantos corporais radiantes e uma satisfação somática extremamente feliz" foi intencionalmente enigmática e ambígua. Eu escrevi aquela frase como uma discreta

\footnotetext{
${ }^{13}$ Em seu livro Consciência Corporal (Rio de Janeiro: É Realizações, 2012), Shusterman dedica capítulos inteiros comentando Foucault, Dewey e James, além de Merleau-Ponty, Simone de Beauvoir e Wittgenstein.

${ }^{14}$ Para ler mais sobre o ponto de vista de Shusterman sobre a filosofia como arte da vida, leia do autor o livro Practicing Philosophy: pragmatism and the philosophical life, New York: Routledge, 1997.

15 "childhood raptures of radiant bodily charms and blissful somatic fulfillment that branded me with a continuous yearning for beauty, long before I knew of any distinction between body and soul", no original em inglês.

${ }^{16}$ Para saber mais sobre o processo de mudança da filosofia analítica para a pragmatista de Richard Shusterman, leia o capítulo "Somaesthetics and the Limits of Aesthetics" do livro de autoria dele: Thinking through the body: essays in somaesthetics. New York: Cambridge University Press, 2012.
} 
homenagem à minha mãe que morreu em 2005. Eu lembro quão bela ela parecia para mim na minha infância e quão feliz eu era quando ela me segurava em seus braços. Sua beleza delicada, graciosa e reconfortante - tanto física quanto espiritual e afetivamente (ela era uma pessoa amorosa e calorosa) - me ensinou, eu acho, a amar a beleza em geral. E não somente amar a beleza e buscá-la, mas também a confiar nela e a respeitá-la. Dedicar minha carreira profissional à Estética é uma indicação óbvia desse amor e dessa confiança.

Crescer e sair de casa significou separar-me desse referencial de beleza e amor. Não foi fácil viver sem ela e, retrospectivamente, eu vejo como tentei encontrar substituições para ela em outras mulheres com qualidades similares de beleza e graça e capacidades de ternura delicada e amorosa: muitas dessas mulheres, sem surpresa, eram dançarinas que tinham experiência em práticas somáticas que elas, então, encorajaram-me a aprender e a praticar, as quais me ajudaram a formatar minha pesquisa em Somaestética. Algumas dessas dançarinas tinham uma sabedoria somática que me encantava, mas elas não eram capazes de expressá-la conceitualmente, então eu decidi usar meu treinamento conceitual para tentar transmitir as suas sábias percepções. Meu livro "Vivendo a Arte" foi dedicado a três dessas graças. A sensibilidade somaestética que eu aprendi com elas foi uma contrapartida útil ao intenso treinamento somaestético da minha carreira militar.

E - Em um dos seus ensaios que posteriormente se tornaria o capítulo de abertura do livro 'Thinking through the body', você afirma que:

O corpo não é só uma dimensão essencial da nossa humanidade, é também o instrumento básico de toda a performance humana [...], nós precisamos de um melhor conhecimento somático para melhorar a compreensão e performance nas artes, nas ciências sociais e para o avanço da mestria na mais alta forma de arte - aquela relativa ao aperfeiçoamento da nossa humanidade e ao viver de uma vida melhor. Precisamos pensar cuidadosamente através do corpo de modo a nos cultivarmos e a edificar nossos estudantes [...] (SHUSTERMAN, 2011, p. 6-7) ${ }^{17}$.

Nós acreditamos que este caminho somático não é simples, habitual ou algo encorajado em nossa cultura ocidental (ou ocidentalizada). A ideia da Somaestética e seu projeto são essencialmente utópicos? Pensando nas crianças, nos jovens, nas pessoas comuns, como podemos nos dedicar a um projeto somaestético de forma a tornar possível esse "viver melhor"?

R.S. - Eu caracterizaria o projeto somaestético mais como meliorista ou meliorativo do que utópico. Não é simplesmente uma ideia utópica, se com isso você quer dizer algo que não possa ser alcançado na vida real, mas somente esperado ou desejado. Eu penso que a cultura ocidental está de fato cada vez mais preocupada com o aprimoramento somaestético: há mais atenção à alimentação saudável e a formas de exercício e técnicas meditativas de consciência e harmonia corpo-mente do que havia em muitas décadas atrás. É claro que há espaço

17 SHUSTERMAN, R. Pensar Através do Corpo, Educar para as Humanidades: Um Apelo para a Soma-Estética. Philia\&Filia, Porto Alegre, vol.02, n.2, jul./dez. 2011. 
considerável para mais aprimoramentos em termos de consciência corporal. Mas nós não devemos deixar de reconhecer o progresso gradual que está sendo feito. $O$ meliorismo pragmatista da somaestética está conectado ao pluralismo pragmatista que reconhece o valor de aprimoramentos fragmentados e de progressos graduais. Há muitos modos de ajudar crianças e pessoas comuns a aprimorarem as suas atenções ao corpo e suas aptidões somaestéticas: instruir sobre nutrição e exercício são duas categorias gerais relacionadas ao como tornar possível o "melhor viver".

Tome como exemplo as crianças: nós podemos ensiná-las sobre bons hábitos alimentares, podemos ensiná-las a jogar jogos, praticar esportes ou tocar músicas que incentivem a consciência corporal. Pessoas que amam tocar instrumentos ou simplesmente amam cantar podem aprender como podem tocar ou cantar melhor ao aprimorarem seus usos do corpo (na postura, ou no movimento, ou na respiração) a partir de suas experiências de tocar ou cantar com foco na sua consciência corporal.

\section{E - No prefácio do seu livro 'Consciência Corporal', você diz:}

[...] Hoje, quando a filosofia deixou de ser uma arte de vida global e passou a ser um campo estreito de discurso acadêmico, o corpo ainda tem uma presença forte enquanto abstração teórica (e, às vezes, fortemente política). Todavia, a ideia de usar seu cultivo para ampliar a consciência e a intuição filosófica provavelmente chocaria a maioria dos filósofos profissionais, como se fosse uma vergonhosa aberração. Espero alterar esse preconceito (SHSUTERMAN, 2012a, p. 16).

Quase dez anos depois da publicação desse livro ${ }^{18}$ e vinte anos após a publicação do seu primeiro livro propondo a Somaestética como uma disciplina filosófica, há agora pessoas estudando-a em todo o mundo. Você acredita que a Somaestética, uma disciplina filosófica como proposta por você, alcançou o seu objetivo? Você acredita que os filósofos agora estão mais atentos do que costumavam estar ao papel central do soma em nossas vidas?

R.S. - Sim, a Somaestética teve uma recepção surpreendentemente boa desde que eu a introduzi pela primeira vez há vinte anos, quando ela foi recebida com surpresa e até mesmo com alguma crítica na imprensa alemã que zombou do conceito (a primeira vez que utilizei o termo foi num livro alemão publicado em $\left.1996^{19}\right)$. Mas eu devo dizer, em resposta à sua pergunta, que eu não considero mais a Somaestética simplesmente como uma disciplina filosófica, embora tenha sido assim que eu a tenha concebido originalmente. Agora eu reconheço que a Somaestética é um projeto completamente interdisciplinar que se estende para além das fronteiras da Filosofia. Um dos desenvolvimentos mais interessantes em

\footnotetext{
18 O livro original em inglês foi publicado em 2008.

19 Trata-se do livro escrito por ele e intitulado Vor der Interpretation: Sprache und Erfahrung in Hermeneutik, Dekonstruktion und Pragmatismus, editado pela Passagen-Ferlagen em 1996. O termo Somaestética aparece no fim do livro, na página 132, ainda sem muito detalhamento do conceito. $O$ conceito foi apresentado de maneira mais completa somente no artigo Somaesthetics: A Disciplinary Proposal. The Journal of Aesthetics and Art Criticism, vol. 57, n. 3, pp. 299-313, Summer 1999, posteriormente traduzido para o português com o título "Pensar através do corpo, educar para as Humanidades: um apelo para a Soma-Estética”. Philia\&Filia, Porto Alegre, vol.02, n.2, jul./dez. 2011.
} 
Somaestética nos anos recentes se dá no campo da tecnologia digital interativa. Tem havido até alguns protótipos de produtos projetados com o uso da Somaestética. Aqui está um link para um vídeo que apresenta um projeto desse tipo, elaborado por um grupo de pesquisadores de design suecos com quem eu trabalhei e que colaboram com a IKEA e outras empresas de design comercial: $<$ https://www.youtube.com/watch?v=uHTv YaFjEk>. Este desenvolvimento surpreendeu-me, porque eu inicialmente concebi a Somaestética em termos de técnicas ou disciplinas muito orgânicas ou naturais (yoga, meditação zen, tai chi, Método Feldenkrais e Técnica de Alexander - nenhuma delas emprega dispositivos eletrônicos ou codificação computadorizada), mas o campo do design de interação humano-computador é uma das áreas onde a Somaestética tem experimentado um crescimento mais rápido e onde eu tenho dado a maior parte das minhas oficinas práticas mais recentes. As outras oficinas são geralmente organizadas por pessoas das artes performáticas: Dança, Música e Teatro.

E - No campo das artes performáticas, a questão do corpo é algo muito importante e para o qual se dedica uma atenção importante. Você nos falou sobre o oferecimento de um workshop no Instituto Grotowski ${ }^{20}$ em 2013. Jerzy Grotowski, como muitos teóricos do teatro, encenadores, diretores e atores, estava muito preocupado com o corpo e desenvolveu um trabalho de preparação de atores fortemente corporal. Sua palestra no Instituto foi sobre memória muscular, consciência corporal e atenção e reflexões sobre a Somaestética. Como foi a recepção à sua visita? Pode nos contar um pouco sobre essa experiência?

R.S. - Sim, foi uma grande honra realizar uma oficina prática de dois dias e uma palestra no Instituto Grotowski, na Breslávia, Polônia, em 2013. Cinco dos meus livros, incluindo "Consciência Corporal" e "Thinking through the Body21", foram traduzidos para o polonês, então meu trabalho é bem conhecido lá também nos círculos artísticos. Eu admiro profundamente o trabalho de Grotowski e foi uma experiência enriquecedora trabalhar com artistas tão bem treinados e conscientes de seus corpos (eles eram também um grupo muito internacional, então não houve problema em ministrar a oficina em inglês). Eu acredito que o encontro tenha sido um sucesso, porque o Instituto convidou-me a voltar para fazer uma oficina e palestra similares em 2016, quando seu orçamento permitiu. Eu preciso explicar-lhes que as minhas oficinas são mais dispendiosas (em tempo, energia e dinheiro) do que as palestras convencionais, porque elas duram ao menos dois dias e envolvem ao menos cinco horas por dia de intensa concentração e disciplina (tanto minha quanto dos participantes).

E - Você também tem trabalhado com artistas visuais, assim como com músicos. Como você acredita que a Somaestética pode se relacionar com as Artes? Quais questões podem ser levantas pelo estudo da Somaestética por aqueles que estão no campo das Artes?

\footnotetext{
20 O Instituto Grotowsky, em Breslávia, Polônia, é dedicado aos estudos teatrais a partir do legado da obra de Jerzy Grotowsky, teórico do teatro e encenador. Sua prática era fortemente corporal e centrada no trabalho do ator, acreditando no que ele chamava de "teatro pobre", no qual figurino, cenário, iluminação assim como qualquer acessório seria dispensável, pois somente o ator é necessário para expressar essa arte. Para saber mais, acesse 0 site da instituição: <http://en.grotowski-institute.art.pl/>. Acesso em: 10 ago. 2017.

21 "Pensando através do corpo" poderia ser a tradução desse título que ainda não foi traduzido para o português.
} 
R.S. - Como tenho repetido em diversos textos, o soma é o meio mais básico e o instrumento essencial para toda a nossa percepção e performance, então, com um melhor domínio de nosso meio ou ferramenta somática básica, nós podemos conquistar maior domínio nas diversas possibilidades artísticas utilizadas nas mais diferentes formas de arte. Melhor consciência corporal pode dar-nos maior atenção e sensibilidade à nossa condição pessoal (tanto interna quanto externa) e ao nosso ambiente (tanto físico quanto social), e esta atenção e sensibilidade aumentadas podem, em troca, alimentar a nossa imaginação e aprimorar a nossa interação com o público com o qual nós, como artistas, nos relacionamos.

Você talvez não saiba que a Somaestética me levou até a uma - embora pequena - carreira artística. Desde junho de 2010 eu tenho feito experiências em performance, criando e incorporando o personagem estranho e silencioso L'homme en or (o Homem vestindo Ouro), um filósofo sem palavras. Só recentemente, em dezembro de 2016, eu publiquei um livro que descreve em texto e imagens as suas aventuras. Este livro é bilíngue (inglês e francês, porque 0 personagem nasceu na França como resultado da minha colaboração com um artista visual francês ${ }^{22}$ ), e é essencialmente uma obra de ficção, um conto ou fábula filosófica, embora sua cronologia e locações sejam baseadas em fatos. Eu espero que o livro alcance o público no Brasil, porque eu sei que os brasileiros apreciam filosofia criativa. Aqui está o link para o website da editora: <http://www.editionshermann.fr/5030-les-aventures-de-l-homme-en-or.html> e aqui o link para ele na Amazon: <https://www.amazon.com/Adventures-Man-Gold-French/dp/2705694226>.

Meu trabalho em performance (no qual eu circulo numa malha de lycra dourada e brilhante, originalmente feita para bailarinos do Ballet de Paris) ajudou-me a pensar mais profundamente em questões de identidade pessoal, ética e política e identidade de gênero, então ajudou o meu pensamento filosófico também fora da esfera da Estética. Este trabalho com performance é parte de minha visão da estética pragmatista que afirma o poder positivo do pensamento híbrido no qual a filosofia e a arte se integram em uma arte de viver filosófica.

E - Na nossa experiência, no Brasil, a maior parte dos professores de canto não está preocupada com o corpo durante o ensino dessa arte, pelo menos não de modo sistemático. Aqueles que atentam para isso geralmente pensam neste corpo de forma compartimentalizada. Então, para nós, ao invés de questionarmos a prática pedagógica, acreditamos que devemos almejar mudanças nos nossos valores pedagógicos. Se pensarmos sobre o corpo numa perspectiva Somaestética, certamente repensaremos a pedagogia vocal e, portanto, nossas ações como educadores. Como esta mudança filosófica pode acontecer num mundo que parece preso a uma visão de corpo própria do século XVI? O que poderia tornar os professores de canto mais atentos ao papel do soma nos nossos processos de ensino-aprendizagem? O que poderia fazê-los pensar somaesteticamente?

R.S. - Em minha própria experiência, o método que é mais bem sucedido em esclarecer professores e estudantes sobre o valor da consciência corporal é o método da Somaestética experiencial: refiro-me a uma oficina prática na qual os estudantes (e seus professores que também estão participando) possam sentir em seus corpos as ideias somaestéticas que meus textos transmitem conceitualmente.

22 Shusterman refere-se a Yann Toma. 
Essa necessidade por aprendizado experiencial é o motivo pelo qual eu ministro oficinas práticas, mesmo que elas sejam muito cansativas para mim. As pessoas aprendem melhor quando elas vivenciam a experiência, quando, na inteireza de seus corpos, vivem as lições que tentam ensinar. Ler os textos não pode fornecer isso de um modo real; de fato, muitas das ideias dos meus textos não podem ser inteiramente conceitualmente compreendidas a menos que a pessoa tenha realmente a experiência somaestética relevante. Eu percebi isso ao checar as traduções de meus livros em idiomas que eu conheço bem o bastante para corrigir a tradução (o francês e o alemão, por exemplo). Em alguns lugares eu descobri que a minha ideia havia sido traduzida erroneamente pelo tradutor porque ele não tinha entendido a sensação ou o movimento que eu descrevia e isso, acredito eu, deve-se ao fato dele nunca tê-los experimentado.

E - Na sua primeira conversa com o André você disse que algumas pessoas tentaram fazer com que você olhasse para o corpo exclusivamente por uma perspectiva subjetiva, o que você sabiamente recusou, por acreditar que o corpo implica numa dualidade de ser objeto e sujeito ao mesmo tempo: como você afirma: eu sou um corpo ao mesmo tempo em que tenho um corpo. Embora nós acreditemos fortemente que você esteja certo, incomoda-nos o fato de que a maior parte dos cantores e professores de canto olhem para o corpo principalmente como um objeto da performance, mantendo suas subjetividades à parte disso. Quais poderiam ser as consequências do não reconhecimento deste papel duplo do corpo no processo de ensino-aprendizagem de atividades motoras ou artísticas como o canto?

R.S. - Acho que a história a que você se refere é sobre os meus amigos da filosofia alemã, que disseram que eu deveria usar o termo "Leib" (a palavra alemã para o sentido subjetivo do corpo, em contraste com "Körper" que significa o corpo objetivo, físico) em vez de usar "soma", quando eu estivesse escrevendo para um público alemão ou quando minha obra estivesse sendo traduzida para o alemão. Eu recusei a sugestão deles porque a Somaestética diz respeito tanto à dimensão subjetiva quanto à objetiva da existência corporal, como o corpo sente por dentro e como ele aparenta por fora. Meu conceito de soma contém e integra ambos os lados destas dualidades, porque estes dualismos, na verdade, estão juntos na experiência da vida real. Subjetividade e objetividade são geralmente conectadas de maneira muito próximas na performance. Eu não tenho treinamento técnico para o canto, mas eu tenho certeza de que a postura física objetiva durante o canto pode ocasionalmente afetar o humor subjetivo (e pode certamente afetar a respiração) e o humor subjetivo pode certamente afetar a qualidade do canto.

A abordagem Somaestética não é uma escolha entre o subjetivo e o objetivo, o interior e o exterior; o espontâneo e o que é refletido criticamente; a abordagem Somaestética é, em vez disso, a combinação e a integração - com sobreposições bem sucedidas em diferentes momentos ou estágios - de ambos os elementos destes dualismos.

E - Gostaríamos de encorajar os cantores e professores de canto a enxergarem o todo de seus corpos, ou, ainda melhor, o soma, de forma a trazer a ideia de um "corpo ou subjetividade corporal vivente, intencional, senciente e perceptivo". Então nós temos pensado que talvez possamos olhar para o corpo como lócus da performance e da percepção somática, de forma que seja possível abarcar a ideia de um corpo sujeito sem negligenciar a ideia do corpo como 
instrumento. Você também nos traz a ideia do corpo como lócus em "Thinking through the body" quando afirma:

[...] por causa do dualismo corpo/mente entranhado profundamente em nossa cultura, a simples noção de corpo sugere mera massa material e ausência da mente, o que faz da 'filosofia do corpo' parecer um contraste à filosofia da mente. Eu busco superar tal dualismo reconhecendo o corpo como lugar de percepção ativa e subjetividade (SHUSTERMAN, 2012b, p. 5).

Você acredita que reconhecer o corpo como lugar ou lócus da ação e percepção possa ajudar-nos a superar a dualidade objeto/sujeito da mesma forma que ajuda a superar a dualidade corpo/mente?

R.S. - Sim, mas eu também acredito que seja importante usar o termo "soma" para fazer esse trabalho de mostrar essa dimensão intencional, perceptiva, senciente, dinamicamente ativa e inteligente da vida corporal. Na Filosofia as palavras são consideradas importantes, pois são veículos da formação do pensamento. Parte do valor da Somaestética está no modo como o termo ou o conceito remodela nossa percepção do papel do corpo na experiência, incluindo, em particular, a experiência estética. Com a ideia de soma esse papel não é simplesmente aquele de um objeto de apreciação estética (atrativamente bronzeado e modelado num traje de banho revelador); ela também inclui o papel da subjetividade ao aproveitar da sua própria experiência somaestética da praia: um soma que se excita com cada sopro de ar fresco do oceano, como ele se sente com - calor do sol, como os seus suaves movimentos de alongamento dissolvem gradualmente as tensões musculares. Como pano de fundo, isso gera um poderoso prazer estético de estar feliz e completamente vivo e atento ao eu somático e as suas agradáveis relações com o seu mundo.

Obviamente as minhas palavras aqui, não importa quantas eu use e quão fortemente eu tente fazê-las evocar a experiência da praia, não conseguem capturar adequadamente a sensação dessa experiência estética e o seu prazer. Isso não significa que as minhas palavras nesta entrevista sejam imprestáveis para transmitir o significado da Somaestética. Isso significa, entretanto, que palavras não podem prover o significado completo da teoria Somaestética, embora palavras sejam até mesmo necessárias para conduzir oficinas de Somaestética prática e exercícios que fornecem esse significado mais amplo. Aqui a Somaestética trabalha para integrar outro dualismo que atrapalhou a filosofia - o linguístico versus o não-linguístico.

\section{Referências}

HANNAH, Thomas. What is somatics? Journal of Behavioral Optometry, Maryland, v. 2, n. 2, p. 31-35, 1991.

SHUSTERMAN, Richard. Vor der Interpretation: Sprache und Erfahrung in Hermeneutik, Dekonstruktion und Pragmatismus. Passagen-Ferlagen, 1996. 
Practicing Philosophy: pragmatism and the philosophical life. New York: Routledge, 1997.

Somaesthetics: A Disciplinary Proposal. The Journal of Aesthetics and Art Criticism, vol. 57, n. 3, pp. 299-313, Summer 1999.

Pensar através do corpo, Educar para as Humanidades: Um apelo para a Soma-estética. Philia\&Filia, Porto Alegre, vol. 02, n.2, jul./dez. 2011.

Consciência Corporal. Trad.: Pedro Sette-Câmara. Rio de Janeiro: É. Realizações, 2012a.

Thinking Through the Body: Essays in Somaesthetics. New York: Cambridge University Press, 2012b.

STRAUCH, Ralph. An overview of the Feldenkrais Method. 1996. Disponível em: <http://www.somatic.com/articles/feldenkrais_overview.pdf>. Acesso em: 10 ago. 2017. 